\title{
Time- and cycle-dependent crack propagation in Haynes 282
}

\author{
Jonas Saarimäki ${ }^{\mathrm{a}, *}$, Johan J. Moverare ${ }^{\mathrm{a}}$, Magnus Hörnqvist Colliander ${ }^{\mathrm{b}, \mathrm{c}}$ \\ ${ }^{a}$ Division of Engineering Materials, Department of Management and Engineering, Linköping \\ University, SE-58183 Linköping, Sweden \\ ${ }^{b}$ Chalmers University of Technology, Department of Applied Physics, 41296 Göteborg, Sweden \\ ${ }^{c}$ GKN Aerospace Engine Systems, RET Centre, 46181 Trollhättan, Sweden
}

\begin{abstract}
Haynes 282 is a promising superalloy candidate for several high-temperature applications in both aero and land-based gas turbine engines. To study the crack growth behaviour under time-dependent conditions relevant to such applications, a test program was carried out at room temperature up to $700{ }^{\circ} \mathrm{C}$ with conditions ranging from pure cyclic to sustained tensile loading. At $650{ }^{\circ} \mathrm{C}$ and high stress intensity factors the crack growth was fully time-dependent for dwell-times of $90 \mathrm{~s}$ and longer. At lower stress intensities, the behaviour was mainly controlled by the cyclic loading, even under dwell conditions. The behaviour under dwell-fatigue conditions was well described by a liner superposition model. The main crack growth occurred transgranularly at room temperature and there was a transition in cracking behaviour from cycle dependent transgranular growth to time-dependent intergranular propagation at $\sim 45 \mathrm{MPa} \sqrt{\mathrm{m}}$ for the high temperature tests. No effect of cyclic frequency could be observed at room temperature, and at lower frequencies the crack growth rate increased with temperature.
\end{abstract}

Keywords: Nickel based superalloys, Fatigue, Fracture, Mechanical characterisation, Electron microscopy

\footnotetext{
*jonas.saarimaki@liu.se +46 13281193
} 


\section{Introduction}

Haynes 282 is a newly developed $\gamma^{\prime}\left(\mathrm{Ni}_{3}(\mathrm{Al}, \mathrm{Ti})-\mathrm{L}_{2}\right)$ strengthened Ni-base superalloy, exhibiting good creep strength, thermal stability, weldability, and fabricability, compared to e.g. Waspaloy [1]. It is a candidate for several high-temperature applications in both aero- and land-based gas turbine engines, as well as steam turbines, ultra super critical power plants, and automotive applications.

In such components, combinations of high temperatures $\left(\sim 550-800{ }^{\circ} \mathrm{C}\right)$ and sustained periods of high tensile loads can lead to accelerated crack growth rates. Under these conditions, the influence of an oxidising environment has long been recognised and the accelerated crack growth rate is often accompanied by a change in crack growth mechanism from transgranular to intergranular crack paths. This is especially true for fine grained and high strength alloys [2-5]. For lower strength alloys, the effects of creep deformation on crack growth should be considered carefully since stress relaxation ahead of the crack tip lead to blunting which will lower the mechanical driving forces [6-8]. A similar retardation effect has also been observed when an overload is applied prior to the dwell-time [9].

At this point in time, detailed information regarding the high-temperature properties of Haynes 282, and in particular the fatigue, dwell-fatigue and sustained load crack growth resistance, is very limited. The effect of temperature and loading frequency has been investigated in [10-13] but to the author's best knowledge, no

studies on the effect of dwell-times on the fatigue crack propagation in Haynes 282 are available.

In the study by Buckson and Ojo [10], the fatigue crack growth behaviour of Haynes 282 at room temperature and at $600{ }^{\circ} \mathrm{C}$, was studied using the stress ratios 
$R=0.1$ and $R=0.7$ and the frequencies $0.05 \mathrm{~Hz}$ and $15 \mathrm{~Hz}$. They concluded that an increase in load ratio increased the fatigue crack growth rates, as expected. They also reported that the fatigue crack growth rate would be influenced by frequency at room temperature, and that there would be an inverse effect of temperature at low test frequencies, which is somewhat contradictory to common assumptions.

In [11-13] by Rozman et al. the fatigue mechanisms of Haynes 282 at high temperatures are characterised, by evaluating the fatigue crack growth rates at three different temperatures, $550{ }^{\circ} \mathrm{C}, 650{ }^{\circ} \mathrm{C}$, and $750{ }^{\circ} \mathrm{C}$ and two loading frequencies, $0.25 \mathrm{~Hz}$ and $25 \mathrm{~Hz}$. It was found that the effect of frequency on the fatigue crack growth rates was minor at $550{ }^{\circ} \mathrm{C}$ but much more significant at $650{ }^{\circ} \mathrm{C}$ and $750{ }^{\circ} \mathrm{C}$. For the temperatures investigated the effect of decreasing the loading frequency was an increase in fatigue crack growth rate. The crack path was observed to be transgranular for the temperatures and frequencies used. Except at $750{ }^{\circ} \mathrm{C}$, where there were indications of limited intergranular cracking excursions at both loading frequencies [12].

The present study is partly motivated by the somewhat controversial results regarding the effects that temperature and frequency have on the fatigue crack growth behaviour reported by Buckson and Ojo in [10]. But also due to the complete lack of studies on dwell-fatigue crack growth in Haynes 282. Rozman et al. [12] pointed out that although the behaviour of Haynes 282 could be considered as robust and predictable within the tested temperature and frequency range, there is a great risk associated with the introduction of dwell-times and sustained loads, which has not been studied so far. For this reason, a test program was carried out to characterise the fatigue, dwell-fatigue and sustained load crack growth resistance of Haynes 282 at room temperature, 650 , and $700{ }^{\circ} \mathrm{C}$. Detailed metallographic investigations of the tested samples were performed to determine the crack growth mechanisms. 


\section{Experimental procedure}

The material used in this study was Haynes 282 delivered in the form of a forged ring, heat-treated accordingly: solution heat treated for 2 hours at $1100{ }^{\circ} \mathrm{C}$ then aged for 2 hours at $1010{ }^{\circ} \mathrm{C}$, with a final aging treatment at $788^{\circ} \mathrm{C}$ for 8 hours. The material had a chemical composition as shown in Table 1 and an average grain size of $120 \mu \mathrm{m}$ or $\# 3$ according to ASTM-E112.

All tests were performed according to ASTM E647 using the compliance method for crack length measurements at ambient temperature while the potential drop (PD) technique was used at elevated temperatures $\left(650{ }^{\circ} \mathrm{C}\right.$ and $700{ }^{\circ} \mathrm{C}$ ). The specimen and PD-instrumentation is illustrated in Fig. 1 (a). Testing was done using compact tension (CT) specimens measuring: Width $W=25 \mathrm{~mm}$, Fig. 1 (c), and a full thickness $B=12.5 \mathrm{~mm}$, Fig. 1 (b) however, side-grooves were used for all tests giving a net section thickness of $B_{n}=9.5 \mathrm{~mm}$, Fig. 1 (b). The specimens had an electro-discharge machined starter notch measuring $a_{n}=12.5 \mathrm{~mm}$, Fig. 1 (c), and were fatigue pre-cracked at room temperature to a crack length of $a_{0}=16 \mathrm{~mm}$ using a frequency of $10 \mathrm{~Hz}$, a load range of $\Delta P=P_{\max }-P_{\min }=2500 \mathrm{~N}$, and a load ratio of $R=P_{\min } / P_{\max }=0.1$.

Room temperature fatigue crack propagation tests were performed using different stress ratios $(R=0.1$, and $R=0.5)$ and different frequencies $(f=0.05 \mathrm{~Hz}, 1 \mathrm{~Hz}$, and $15 \mathrm{~Hz}$ ). In all tests a load range of $2.5 \mathrm{kN}$ were used. The crack opening displacement was measured using an Instron clip gauge extensometer and the crack growth rates were evaluated according to ASTM E647. Table 2 summarises all the parameters used for the tests run at room temperature.

High temperature crack propagation tests were conducted at $650{ }^{\circ} \mathrm{C}$ with differ-

ent dwell-times (90 s and $2160 \mathrm{~s}$ ), as well as under sustained load conditions, with a 
constant ramp up/ramp down rate yielding $10 \mathrm{~s}$ single ramp time each for loading and unloading. At $700{ }^{\circ} \mathrm{C}$ only sustained load tests were performed. Testing was done using a $100 \mathrm{kN}$ Zwick servo electric tensile testing machine (Kappa 50DS), equipped with a three zone (high temperature) furnace. Table 3 summarises all the parameters used for the tests run at elevated temperature. All tests were performed according to ASTM E647 using a 20 A pulsed direct current potential drop (DCPD) system where crack lengths were obtained by using the Johnson formula, according to

$$
a=\frac{2 W}{\pi} \cos ^{-1} \frac{\cosh \left(\frac{\pi y}{2 W}\right)}{\cosh \left[\frac{U}{U_{0}} \cosh ^{-1}\left(\frac{\cosh \frac{\pi y}{2 W}}{\cos \frac{\pi a_{0}}{2 W}}\right)\right]},
$$

where $U_{0}$ and $a_{0}$ are the initial values of the potential and the crack length, respectively, while $U$ and $a$ are the actual values of the potential and the crack length, $y$ is one half of the gauge span for $U$ and $W$ is the sample width. The analytical solution of the stress intensity factor, $K$, for CT-specimens with side grooves was obtained from ASTM E399, according to

$$
K=\frac{P}{\sqrt{B \cdot b_{n} \cdot W}} f\left(\frac{a}{W}\right)
$$

where:

$f\left(\frac{a}{W}\right)=\frac{\left[2+\frac{a}{W}\right]\left[0.886+4.64\left(\frac{a}{W}\right)-13.32\left(\frac{a}{W}\right)^{2}+14.72\left(\frac{a}{W}\right)^{3}-5.6\left(\frac{a}{W}\right)^{4}\right]}{\left(1-\frac{a}{W}\right)^{\frac{3}{2}}}$.

The tests were stopped at an approximate crack length of $20 \mathrm{~mm}$, after which some specimens were sectioned as-is, perpendicular to the centreline of the crack, so that the crack path could be studied in a cross-section. These samples were 
prepared by grinding and careful mechanical polishing but no etching. A number of specimens were also pulled to fracture and used for studies of the fracture surfaces. A Hitachi SU70 FEG analytical scanning electron microscope (SEM), operating at 1.5-20 kV was used together with Electron Channelling Contrast Imaging (ECCI) [14] to get high quality, high contrast pictures of the crack growth appearance and the microstructure.

\section{Results}

\subsection{Crack growth experiments}

In Fig. 2 (a), the crack growth rate $d a / d N$ at room temperature is plotted versus the stress intensity factor range $\Delta K=K_{\max }-K_{\min }$ for the frequencies $0.05 \mathrm{~Hz}$, $1 \mathrm{~Hz}$, and $15 \mathrm{~Hz}$, all with a load ratio of $R=0.1$, where $a$ is crack length and $N$ is cycles. The change in frequency has no striking effect on the crack growth rate, which can be clearly seen in the enlarged area in the upper left corner of Fig. 2 (a). The crack growth rate is more so affected by the $R$ value as seen in Fig. 2 (b) where the crack growth rate $d a / d N$ is plotted versus the stress intensity factor range $\Delta K$ for two tests run at room temperature, at $15 \mathrm{~Hz}$, but with the different $R$ values, 0.1 and 0.5. In Fig. 3 (a), the crack growth rate $d a / d N$ at $650{ }^{\circ} \mathrm{C}$ is plotted versus the stress intensity factor range $\Delta K$ for two tests with $R=0.05$ and dwell-times of 90, and $2160 \mathrm{~s}$, showing that an increase in dwell-time drastically affects the crack growth rate.

Figure 3 (b) shows the crack growth rate in terms of $d a / d t$ plotted versus the maximum stress intensity factor $K_{\max }$ for the $650{ }^{\circ} \mathrm{C}$ dwell-time tests together with the sustained load test. The major difference can be seen in the low $K_{\text {max }}$-region $\left(K_{\max } \lesssim 50\right)$ where a substantial influence of the cyclic part on the crack growth 
rate can be seen. Since the $90 \mathrm{~s}$ dwell-time shows higher $d a / d t$-values compared to the $2160 \mathrm{~s}$ dwell-time test and the sustained load test. In the high $K_{\text {max }}$-region $\left(K_{\max } \gtrsim 50\right)$, the crack growth rate for the $90 \mathrm{~s}$ dwell test and the $2160 \mathrm{~s}$ dwell test converge with the rate for the sustained load test, indicating that the crack growth rates are primarily time-dependent. The fact that both dwell-time tests converge at roughly the same $K$-level could indicate that there is a threshold below which the time dependent effects do not fully develop.

Another indication of the presence of a threshold for time-dependent crack growth is that the sustained load curve seems to drop off at $K_{\text {max }}$-values around $45 \mathrm{MPa} \sqrt{\mathrm{m}}$. A similar drop-off is seen in the sustained load test performed with $5 \mathrm{kN}$ load at $700{ }^{\circ} \mathrm{C}$ (Fig. 4). Such behaviour does not necessarily correspond to true thresholds, since it can be related to the transient behaviour at the start of the test [15]. In such situations the apparent threshold levels are only related to the $K_{\max }$ level at the start of the test, and not to an inherent crack growth resistance. If the load level at the start of a sustained load test is reduced to below the apparent threshold (under otherwise identical conditions) the crack growth rate decreases until the crack is arrested (as for the $4.5 \mathrm{kN}$ sustained load test in Fig. 4). This indicates that the observed threshold could be a measure of the true resistance to time-dependent crack growth, which is reflected in the transition in the dwell-fatigue tests. Fig. 4 shows that the sustained load crack growth rates at $650{ }^{\circ} \mathrm{C}$ and $700{ }^{\circ} \mathrm{C}$ follow the same trend, with the $650{ }^{\circ} \mathrm{C}$ test being the slower of the two.

\subsection{Fracture mechanisms}

For the room temperature tests, the typical appearance of the crack path and the crack tip in the cross-sectioned specimen is shown in Fig. 5 (a) and (b), respectively. Crack growth at room temperature is mainly transgranular, and surrounding the 
crack path, slip bands, and plastically deformed areas can be seen. In Fig. 5 (c), the crack tip is shown, with "serrations" of the crack path of the same size as the crack extension per cycle at the end of the test (Fig. 2 (a)). The typical fracture surface appearance of a fatigue sample run at room temperature is shown in Fig. 6, where it can be seen that the main crack growth mechanism is transgranular.

For the elevated temperature tests, the typical cracking behaviour was mainly intergranular, particularly for the longer $2160 \mathrm{~s}$ dwell-time, as seen for the crosssectioned sample in Fig. 7. Despite the intergranular cracking behaviour, slip bands and plastically deformed material surrounds the crack path and crack tip, indicating that the fracture of the grain boundaries during crack propagation is not fully brittle. In Fig. 8, the typical appearance of the fracture surface of the $90 \mathrm{~s}$ dwell-time test conducted at $650{ }^{\circ} \mathrm{C}$ is shown. Fig. 8(a) corresponds to $\Delta K \approx 40 \mathrm{MPa} \sqrt{\mathrm{m}}$, where fatigue striations can be seen, and the crack propagation is transgranular. A general overview representing the typical fracture surface appearance at $\Delta K \approx 60 \mathrm{MPa} \sqrt{\mathrm{m}}$ is shown in Fig. 8(b). At this point the crack propagation is time-dependent and the corresponding crack path is intergranular. At higher magnification, brittle striations can be observed at crack lengths corresponding to time-dependent propagation, see Fig. 8 (c).

\section{Discussion}

\subsection{Comparison with literature results}

The primary source for comparison of room temperature data is the report by Buckson and Ojo in $[10]^{\mathrm{c} 1}$. Fig. 9 (a) shows a compilation of the data from the present study and from [10]. There is a number of noteworthy differences between

\footnotetext{
c1, and
} 
the data sets, namely: (i) the levels of the fatigue crack growth thresholds; (ii) the frequency dependence of the crack growth rates, and (iii) the $R$-ratio dependence.

In [10], unusually low threshold values $(\sim 1 \mathrm{MPa} \sqrt{\mathrm{m}})$ were recorded at low frequencies $(0.05 \mathrm{~Hz})$. At higher test frequencies the threshold values were in the order of $10 \mathrm{MPa} \sqrt{\mathrm{m}}$. This can be compared to other results from literature for similar Ni-base superalloys, e.g. Waspaloy, where typical values lie in the range 5-15 $\mathrm{MPa} \sqrt{\mathrm{m}}$ [16-18]. Another example is the threshold values of 6-9 $\mathrm{MPa} \sqrt{\mathrm{m}}$ measured in Udimet 720 [19]. Similar to [10], all these values where measured using the load shedding technique, generating conservative threshold levels. Our results, which show apparent threshold levels in the order of $14-16 \mathrm{MPa} \sqrt{\mathrm{m}}$, independent of test frequency, are more consistent with the literature. However, as the current threshold values were not generated using load shedding, they are not directly comparable to the literature data. The higher threshold value in our study is promising, since threshold values around $1 \mathrm{MPa} \sqrt{\mathrm{m}}$ at low frequencies would pose a serious problem for the application of Haynes 282 in fatigue sensitive components. However, in order to understand e.g. the influence of microstructure on crack propagation rates it is necessary to further clarify the behaviour in the threshold and near-threshold region.

As seen in Figs. 2 (a) and 2 (b), the frequency dependence of the crack growth rates and the apparent thresholds were insignificant in the present tests. In [10] a decrease in test frequency from 0.5 to $0.05 \mathrm{~Hz}$ increased the crack growth rates at one order of magnitude at $R=0.1$, and decreased the crack growth threshold from 10 to around $1 \mathrm{MPa} \sqrt{\mathrm{m}}$. A large $R$-ratio effect could be seen at $0.5 \mathrm{~Hz}$, where the cracks grew approximately one order of magnitude faster at $R=0.7$ compared to 0.1 . The results reported here are in stark contradiction to these observations, and these discrepancies require further attention since correct models of how $R$ ratio and frequency effect the crack growth rates are critical for life prediction of 
components. Yet it is not clear how sensitive the fatigue properties of Haynes 282 is to microstructural variations, and since the test methods differ on a number of points between this study and the one by Buckson and Ojo [10] it is difficult to draw firm conclusions at this point.

At elevated temperatures our results and those previously reported in [10-13] are in good agreement, as can be seen in Fig. 9 (b). The experimental data was generated under slightly different test conditions and microstructures, due to which a detailed comparison is difficult, although, the results are in agreement within the expected scatter band of such testing. In the present study, the $2160 \mathrm{~s}$ dwell-time test show the highest crack growth rates. Which is expected given the increased environmental interaction during long dwell-times. The low- $K$ part of the $90 \mathrm{~s}$ dwell-time test falls well within the scatter band of the data from [10-13], supporting the observations that the crack growth is largely controlled by the cyclic part of the wave form in this region i.e., the fatigue part $<45 M P a \sqrt{m}$.

\subsection{Superposition model for dwell-fatigue crack growth}

The fact that the results in the previous section indicate that the crack propagation rate at $650{ }^{\circ} \mathrm{C}$ is mainly controlled by the cyclic part of the dwell-fatigue cycles at low $K$-values and time-dependent at higher $K$ suggests that the total crack propagation behaviour can be described by a simple superposition model as first suggested by Saxena et al. in [20], according to

$$
d a / d N=d a / d N_{c y c l i c}+t_{d w e l l} \cdot d a / d t_{d w e l l}
$$

where the cycle dependency is described by the common Paris law,

$$
d a / d N_{\text {cyclic }}=C \Delta K^{m}
$$


and the time dependency is be described by the following power law equation,

$$
d a / d t_{d w e l l}=A K_{d w e l l}^{n}
$$

In Eq's (4), (5), and (6) $t_{d w e l l}$ [hours] is the length of the dwell-time, $\Delta K[\mathrm{MPa} \sqrt{\mathrm{m}}]$ is the stress intensity factor range for the load reversals and $K_{\text {dwell }}[\mathrm{MPa} \sqrt{\mathrm{m}}]$ is the stress intensity factor during the dwell-time (for our experiments $K_{\text {dwell }}=K_{\max }$ ). The material dependent parameters that needs to be fitted to the experimental data are $C$ and $m$ for the cycle dependency and $A$ and $n$ for the time dependency. In the present modelling work, $C$ and $m$ were calibrated against the slope for the $90 \mathrm{~s}$ dwell-time test in the low $\Delta K$-region, while $A$ and $n$ were calibrated against the sustained load test. As a result the crack propagation rate da/dN [mm/cycle] can be calculated from Eq. (4) - (6) using the material parameters $C=6 \cdot 10^{-7}, m=2$, $A=4 \cdot 10^{-14}$ and $n=7$. The model shows a good fit to the experimental data as can be seen in Fig. 10 for both the $90 \mathrm{~s}$ and the $2160 \mathrm{~s}$ dwell-time tests.

\subsection{Crack growth mechanisms and threshold for time-dependent growth}

In Fig. 8 (c), brittle striations could be observed at crack lengths corresponding to increased crack growth rates. These observations are very similar to the striations observed during environmental hydrogen embrittlement of Ti-alloys [21-24]. In Tialloys, brittle striations have been proposed to be due to the repeated stress assisted formation and fracture of hydride films ahead of growing cracks [22]. The crack growth behaviour in gaseous hydrogen exhibited similar behaviour as Haynes 282 in the present case, including the threshold above which an increased environmental effect could be observed [23, 24]. Li et al. [6], have suggested that the sustained load crack growth in RR1000 at $700{ }^{\circ} \mathrm{C}$ takes place by a similar mechanism involving the repetitive fracture of an oxide film in the grain boundary ahead of the crack, generally 
termed stress accelerated grain boundary oxidation - SAGBO [25]. Such films, with penetration depths of around 1-10 $\mu \mathrm{m}$ ahead of the tip, have been observed in dedicated experiments in several Ni-base superalloys [26-28]. In the present case, the striation spacing is in the order of $2 \mu \mathrm{m}$, which agrees well with the measured oxide intrusion lengths in front of growing cracks in $\operatorname{RR} 1000(\sim 1.5 \mu \mathrm{m})[26]$ and Allvac 718Plus $(\sim 1 \mu \mathrm{m})$ [28].

Assuming that oxidation induced crack growth is the dominating mechanism in the present case, the sustained load crack growth threshold, $K_{t h}$, can, according to Eq. (7) by Chan [29], be calculated as

$$
K_{t h}^{o x}=E_{o x} \epsilon_{f} \sqrt{\frac{t_{o x}}{3\left(1-\nu^{2}\right)}}+2 \sqrt{\frac{E_{o x} \sigma_{y} \epsilon_{t r} t_{o x}}{2\left(1-\nu^{2}\right)}},
$$

where $t_{o x}$ is the oxide film thickness, and the other variables are specified in Table 4 . The fracture strain of $\mathrm{Al}_{2} \mathrm{O}_{3}$ on $\mathrm{TiAl}$ at $700{ }^{\circ} \mathrm{C}$ was measured to around $0.5 \%$ for a surface oxide of around $90 \mu \mathrm{m}$ [30]. The crack tip oxide films observed in experiments are much thinner than the surface scales used for fracture strain assessment in [30], typically less than $100 \mathrm{~nm}$ for growing cracks, and up to $200 \mathrm{~nm}$ for tensile loaded but stationary cracks [26, 27], although thicker oxides $(\sim 1 \mu \mathrm{m})$ ahead of slow growing cracks in RR1000 at $700{ }^{\circ} \mathrm{C}$ have been observed [6]. At $900{ }^{\circ} \mathrm{C}$ the fracture strain increased with decreasing film thickness [30], and assuming a similar relationship at $650{ }^{\circ} \mathrm{C}, \epsilon_{f}$ for $\mathrm{Al}_{2} \mathrm{O}_{3}$ can be taken to be in the order of $1 \%$ for very thin oxides. Similar values could be expected for other oxides, such as $\mathrm{NiO}$ and $\mathrm{Cr}_{2} \mathrm{O}_{3}$. The crack growth threshold was calculated for all three oxides as a function of oxide film thickness, assuming $\epsilon_{f}=1 \%$, and the results are shown in Fig 11. The only case where threshold values in the order of $40 \mathrm{MPa} \sqrt{\mathrm{m}}$, as observed in the present case, can be expected is for relatively thick (500 nm) $\mathrm{Al}_{2} \mathrm{O}_{3}$ films.

In reality the observed oxides are intricately layered, with the details of the lay- 
ering depending on the alloy composition. This makes the situation more complex, compared to the simplified single-type oxide intrusion assumed above. The intrusions ahead of fast growing cracks in RR1000 consisted mainly of inner Co and Ni oxides, with a thin $\mathrm{Cr}_{2} \mathrm{O}_{3}$ layer separating them from the matrix, whereas slow growing crack tips had intrusions composed mainly of $\mathrm{Al}_{2} \mathrm{O}_{3}$ and $\mathrm{Cr}_{2} \mathrm{O}_{3}$ [6]. Another Ni-base alloy showed an inner $\mathrm{MO}$ oxide with $\mathrm{Co}, \mathrm{Fe}$ and $\mathrm{Ni}$, and an outer $\mathrm{M}_{2} \mathrm{O}_{3}$ layer dominated by Cr [28]. Similar results were observed in the Ni-Fe based Alloy 718, with an inner Ni- and Fe-rich oxide and an outer Cr-rich layer [27]. It should be noted that, the calculations above does not consider the relaxation of stresses at the crack tip during the sustained load, which have been argued to increase the crack growth threshold [6, 31]. Haynes 282 have been shown to undergo relatively fast stress relaxation during dwell-fatigue loading at $650{ }^{\circ} \mathrm{C}$ and $730{ }^{\circ} \mathrm{C}$ [32], and thus the values predicted above could be expected to be too low. To further clarify if $\mathrm{Al}_{2} \mathrm{O}_{3}$, or potentially $\mathrm{Cr}_{2} \mathrm{O}_{3}$, could be responsible for the sustained load crack growth, more detailed studies of the crack tip oxides must be undertaken to identify the present oxides.

Another potential mechanism that could explain the sustained crack growth is dynamic embrittlement (DE). In this case, elemental oxygen diffuses ahead of the crack tip and causes a reduced grain boundary decohesion [33]. Chen [29] proposed a similar model to estimate the thresholds associated with dynamic embrittlement, according to

$$
K_{t h}^{D E}=E_{m} \epsilon_{f} \sqrt{\frac{h}{3\left(1-\nu^{2}\right)}},
$$

where $h$ is the width of the embrittled zone around the grain boundary. The other parameters are defined in Table 4 . The critical fracture strain can be calculated as 
a function of the oxygen solubility according to

$$
\epsilon_{f}=\frac{1}{2 \beta C_{o}}=\frac{1}{2 \beta C_{o}} \exp \left(\frac{\Delta H_{s}^{0}}{R T}\right)
$$

which, given the values of the parameters given in [29], results in fracture strains of 7.8-15.6 \% at $650{ }^{\circ} \mathrm{C}$, depending on the value of $\beta$. The resulting threshold values as a function of the embrittled zone thickness are included in Fig. 11. Considering that diffusion of oxygen into the surrounding grains is negligible $[28,34,35], h$ can be assumed to be very small. Thus, the predicted threshold values are too low to account for the observed thresholds of $\sim 45 \mathrm{MPa} \sqrt{\mathrm{m}}$ in this work.

To find significant evidence of oxidation induced cracking has been found rather difficult. Even though these calculations are approximate, they clearly indicate that oxidation induced cracking is a more likely mechanism than dynamic embrittlement during crack growth in Haynes 282 in the temperature range considered in this work. This is further supported by the observation of brittle striations (Fig. 8 (c)) in the region corresponding to increased crack growth rates.

\section{Conclusions}

Crack growth tests was performed on Haynes 282 at room temperature as well as at $650{ }^{\circ} \mathrm{C}$ and $700{ }^{\circ} \mathrm{C}$ under different loading conditions. The purpose was to clarify a number of controversial results previously reported for the same material, and to study the effects of dwell-fatigue and sustained loads on the crack growth behaviour. The following main conclusions can be drawn from this work:

- The crack growth rate was not frequency dependent, contrary to previous results, but more so dependent on the stress ratio $R$, at room temperature, although the $R$-ratio effect was smaller than previously reported. The crack propagated transgranularly in all cases at room temperature. 
- The crack growth rate was purely time-dependent at elevated temperatures at stress intensity factors above $\sim 45 \mathrm{MPa} \sqrt{\mathrm{m}}$. The time-dependent crack growth was suggested to be caused by stress-assisted grain boundary oxidation rather than dynamic embrittlement. At lower stress intensity factors, the behaviour was mainly controlled by the contributions from the loading/unloading sequence.

- In accordance with the observed transition from cycle dependent to timedependent crack growth during the tests with tensile dwell, a change in the crack growth mechanism from transgranular to intergranular was observed.

- The dwell-fatigue behaviour at $650{ }^{\circ} \mathrm{C}$ could be well described by a simple superposition model calibrated against the low $\Delta K$ part of the dwell-fatigue test with a $90 \mathrm{~s}$ dwell-time, and the $5000 \mathrm{~N}$ sustained load test.

\section{Acknowledgements}

The authors would like to thank Agora Materiae, graduate school, Faculty grant SFO-MAT-LiU\#2009-00971, and the project teams at Linköping University, Siemens Industrial Turbomachinery $\mathrm{AB}$ and GKN Aerospace Engine Systems for valuable discussions. This research has been funded by the Swedish Energy Agency, Siemens Industrial Turbomachinery AB, GKN Aerospace Engine Systems, and the Royal

Institute of Technology through the Swedish research program TURBO POWER, the support of which is gratefully acknowledged.

\section{References}

[1] L. M. Pike, H. International, W. P. Ave, Development of a fabricable gammaprime $\left(\gamma^{\prime}\right)$ strengthened superalloy, in: Superalloys 2008, The minerals, metals 
\& materials society, 2008, pp. 191-200.

[2] J. P. Pédron, A. Pineau, The Effect of Microstructure and Environment on the Crack Growth Behaviour of Inconel 718 Alloy at $650{ }^{\circ} \mathrm{C}$ under Fatigue, Creep and Combined Loading, Materials Science and Engineering 56 (1982) 143-156.

[3] J. A. Pfaendtner, C. J. McMahon JR., Oxygen-induced intergranular cracking of a Ni-base alloy at elevated temperatures - an example of dynamic embrittlement, Acta Materialia 49 (16) (2001) 3369-3377.

[4] R. Molins, G. Hochstetter, J. C. Chassaigne, E. Andrieu, Oxidation effects on the fatigue crack growth behaviour of alloy 718 at high temperature, Acta Materialia 45 (2) (1997) 663-674.

[5] E. Andrieu, R. Molins, H. Ghonem, A. Pineau, Intergranular crack tip oxidation mechanism in a nickel-based superalloy, Materials Science and Engineering A 154 (1) (1992) 21-28.

[6] J. Li, H. Wang, H. Tang, Effect of heat treatment on microstructure and mechanical properties of laser melting deposited Ni-base superalloy Rene`41, Materials Science and Engineering: A 550 (2012) 97-102.

[7] J. Byrne, R. Hall, L. Grabowski, Elevated temperature fatigue crack growth under dwell conditions in Waspaloy, International Journal of Fatigue 19 (5) (1997) 359-367.

[8] X. Liu, B. Kang, K. Chang, The effect of hold-time on fatigue crack growth behaviors of WASPALOY alloy at elevated temperature, Materials Science and Engineering A 340 (1) (2003) 8-14. 
[9] J. Saarimäki, J. Moverare, R. Eriksson, S. Johansson, Influence of overloads on dwell time fatigue crack growth in Inconel 718, Materials Science and Engineering: A 612 (2014) 398-405.

[10] R. Buckson, O. Ojo, Cyclic deformation characteristics and fatigue crack growth behaviour of a newly developed aerospace superalloy Haynes 282, Materials Science and Engineering: A 555 (2012) 63-70.

[11] K. A. Rozman, Characterization of High Temperature Fatigue Mechanisms in Haynes 282 Nickel Based Superalloy, Ph.D. thesis, Oregon State University (2014).

[12] K. A. Rozman, J. J. Kruzic, J. A. Hawk, Fatigue Crack Growth Behavior of Nickel-base Superalloy Haynes 282 at $550-750{ }^{\circ} \mathrm{C}$, Journal of Materials Engineering and Performance 24 (8) (2015) 2841-2846.

[13] K. A. Rozman, J. J. Kruzic, J. S. Sears, J. A. Hawk, Fatigue Crack Growth Mechanisms for Nickel-based Superalloy Haynes 282 at $550-750{ }^{\circ} \mathrm{C}$, Journal of Materials Engineering and Performance 282.

[14] R. J. Kamaladasa, Y. N. Picard, Basic Principles and Application of Electron Channeling in a Scanning Electron Microscope for Dislocation Analysis, Microscopy: Science, Technology, Applications and Eduaction (2010) 1583-1590.

[15] I. P. Vasatis, R. M. Pelloux, The effect of environment on the sustained load crack growth rates of forged WASPALOY, Metallurgical Transactions A 16 (8) (1985) 1515-1520.

[16] J. E. King, Fatigue crack propagation in nickel-base superalloys - effects of 
microstructure, load ratio, and temperature, Materials Science and Technology 3 (9) (1987) 750-764.

[17] R. Smith, Y. Liu, L. Grabowski, Short Fatigue Crack Growth Behaviour in Waspaloy At Room and Elevated Temperatures, Fatigue \& Fracture of Engineering Materials and Structures 19 (12) (1996) 1505-1514.

[18] M. Clavel, A. Pineau, Fatigue behaviour of two nickel-base alloys I: Experimental results on low cycle fatigue, fatigue crack propagation and substructures, Materials Science and Engineering 55 (2) (1982) 157-171.

[19] H. T. Pang, P. A. S. Reed, Microstructure variation effects on room temperature fatigue threshold and crack propagation in Udimet 720Li Ni-base superalloy, Fatigue and Fracture of Engineering Materials and Structures 32 (8) (2009) $685-701$.

[20] A. Saxena, R. S. Williams, T. T. Shih, A model for representing and predicting the influence of hold time on fatigue crack growth behavior at elevated temperature, in: Fracture Mechanics: Thirteenth Conference, ASTM STP 743, American Society for Testing and Material, no. 743, 1981, pp. 86-99.

[21] H. G. Nelson, D. P. Williams, J. E. Stein, Environmental hydrogen embrittlement of an alpha-beta titanium alloy - Effect of microstructure., Metallurgical Transactions 3 (2) (1972) 473-479.

[22] H. G. Nelson, A film-rupture model of hydrogen-induced, slow crack growth in acicular alpha-beta titanium, Metallurgical Transactions A 7 (4) (1976) 621-627.

[23] R. Gaddam, R. Pederson, M. Hörnqvist, M.-L. Antti, Fatigue crack growth 
behaviour of forged Ti-6Al-4V in gaseous hydrogen, Corrosion Science 78 (2014) 378-383.

[24] R. Gaddam, M. Hörnqvist, M.-L. Antti, R. Pederson, Influence of high-pressure gaseous hydrogen on the low-cycle fatigue and fatigue crack growth properties of a cast titanium alloy, Materials Science and Engineering: A 612 (2014) 354-362.

[25] W. Carpenter, B. S. J. Kang, K. M. Chang, SAGBO Mechanism on High Temperature of Ni-base Superalloys Cracking Behavior, The Minerals, Metals and Materials Society (1997) 679-688.

[26] H. S. Kitaguchi, H. Y. Li, H. E. Evans, R. G. Ding, I. P. Jones, G. Baxter, P. Bowen, Oxidation ahead of a crack tip in an advanced Ni-based superalloy, Acta Materialia 61 (6) (2013) 1968-1981.

[27] L. Viskari, S. Johansson, K. Stiller, Oxygen influenced intergranular crack propagation: Analysing microstructure and chemistry in the crack tip region, Materials at High Temperatures 28 (4) (2011) 336-341.

[28] L. Viskari, M. Hörnqvist, K. L. Moore, Y. Cao, K. Stiller, Intergranular crack tip oxidation in a Ni-base superalloy, Acta Materialia 61 (10) (2013) 3630-3639.

[29] K. S. Chan, A Grain Boundary Fracture Model for Predicting Dynamic Embrittlement and Oxidation-Induced Cracking in Superalloys, Metallurgical and Materials Transactions A 46 (6) (2015) 2491-2505.

[30] C. Bruns, M. Schütze, Investigation of the Mechanical Properties of Oxide Scales on Nickel and TiAl, Oxidation of Metals 55 (2001) 35-68. 
[31] K. S. Chan, Time-dependent crack growth thresholds of Ni-base superalloys, Metallurgical and Materials Transactions A: Physical Metallurgy and Materials Science 45A (8) (2014) 3454-3466.

[32] R. Brommesson, Modelling of cyclic and viscous behaviour of materials for gas turbine applications - with a view towards fatigue life predictions, Ph.D. thesis, Chalmers University of Technology (2015).

[33] U. Krupp, Dynamic embrittlement - Time-dependent quasi-brittle intergranular fracture at high temperatures, International Materials Reviews 50 (2) (2005) 83-97.

[34] M. Hörnqvist, L. Viskari, K. L. Moore, K. Stiller, High-temperature crack growth in a Ni-base superalloy during sustained load, Materials Science and Engineering: A 609 (2014) 131-140.

[35] S. Perusin, D. Monceau, E. Andrieu, Investigations on the Diffusion of Oxygen in Nickel at $1000^{\circ} \mathrm{C}$ by SIMS Analysis, Journal of The Electrochemical Society 152 (12) (2005) E390. 


\section{List of Figures}

1 A 3D view and specimen drawing of the of an instrumented CT specimen with side grooves. All measurements are in mm. . . . . . . . . . 22

2 Crack growth rate $d a / d N$ vs. $\Delta K$ at $23{ }^{\circ} \mathrm{C}$ for (a) $R=0.1$ and, (b) $f=15 \mathrm{~Hz}$ for $R=0.1$ and $R=0.5$. . . . . . . . . . . . . . . . . . . 23

3 (a) Crack growth rate $d a / d N$ vs. $\Delta K$ at $650{ }^{\circ} \mathrm{C}$ for $R=0.5$, and dwelltimes of $2160 \mathrm{~s}$ and $90 \mathrm{~s}$. (b) Time dependent crack growth, $d a / d t$ vs. $K_{\max }$ at $650{ }^{\circ} \mathrm{C} \ldots \ldots \ldots \ldots 24$

4 Sustained load crack growth rate $d a / d t$ vs. $K_{\max }$ at $700{ }^{\circ} \mathrm{C} \quad(650$ ${ }^{\circ} \mathrm{C}$ data included for comparison). There is an apparent threshold at $K_{\text {max }} \approx 45 \mathrm{MPa} \sqrt{\mathrm{m}}$, below which the crack growth is arrested. . . . . 25

5 A room temperature fatigue sample run with a sinusoidal test frequency of $f=0.05 \mathrm{~Hz}$ and stress ratio $R=0.1$ showing: (a) The crack tip. (b) The regular cracking behaviour being transgranular. (c) The crack tip and cycle length. . . . . . . . . . . . . . . . . . 26

6 The general fracture surfaces of a fatigued room temperature sample. 27

7 The $650{ }^{\circ} \mathrm{C}, 2160 \mathrm{~s}$ dwell-time sample showing: (a) The regular cracking behaviour being intergranular. (b) The crack tip. . . . . . . . . . 28

8 Fracture surfaces of the $90 \mathrm{~s}$ dwell-time sample, the fatigue part taken before the transition between cyclic and time-dependent crack growth, at $\sim 40 \mathrm{MPa} \sqrt{\mathrm{m}}$, and after the transition at $\sim 60 \mathrm{MPa} \sqrt{\mathrm{m}}$ (a) Fatigue striations.(b) The creep area, $d a / d t$. (c) Brittle striations. . . . . . .

9 (a) A comparison of our room temperature tests (dots) with data fitted from [10] by Buckson and Ojo (dashed lines) noted [B]. (b) A comparison of our dwell-time tests (dots) with data fitted from [11-13] by Rozman (dashed lines) noted [R], and from [10] by Buckson and

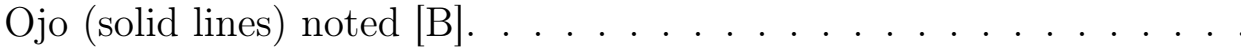

10 A simple model of the $650{ }^{\circ} \mathrm{C}$ dwell-fatigue crack growth based on the low- $K$ part of the $90 \mathrm{~s}$ dwell-time test and the sustained load test, showing a good fit to both the $90 \mathrm{~s}$ dwell-time test as well as the $2160 \mathrm{~s}$ dwell-time test. . . . . . . . . . . . . . . . . . . . 31

11 Predicted crack growth threshold as a function of oxide film or embrittled zone thickness. . . . . . . . . . . . . . . . . 
a)

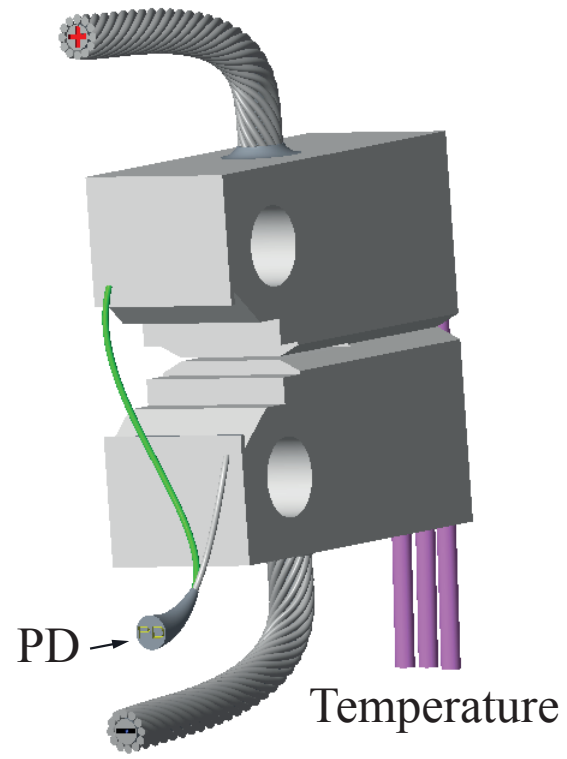

b)

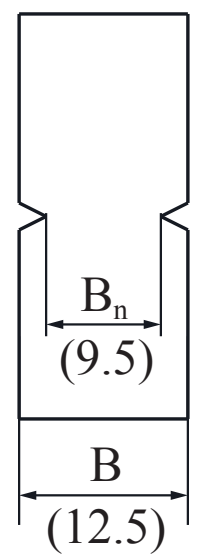

c)

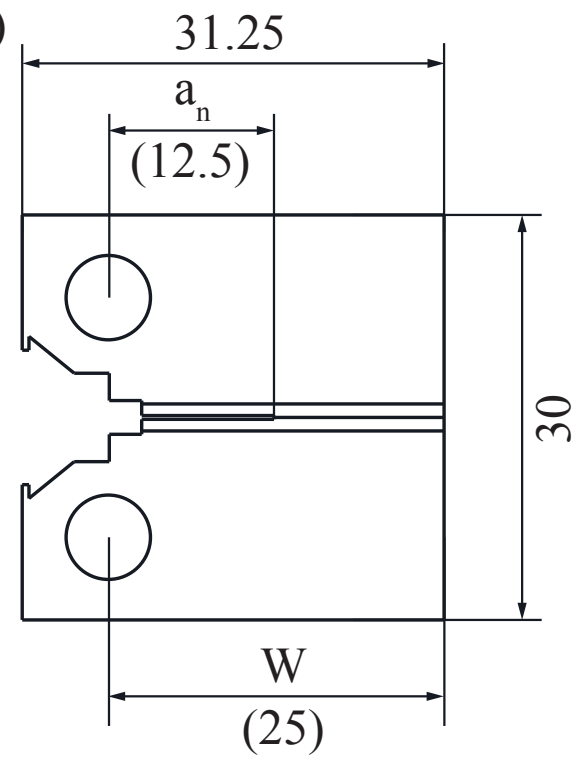

Figure 1: A 3D view and specimen drawing of the of an instrumented CT specimen with side grooves. All measurements are in $\mathrm{mm}$. 
a)

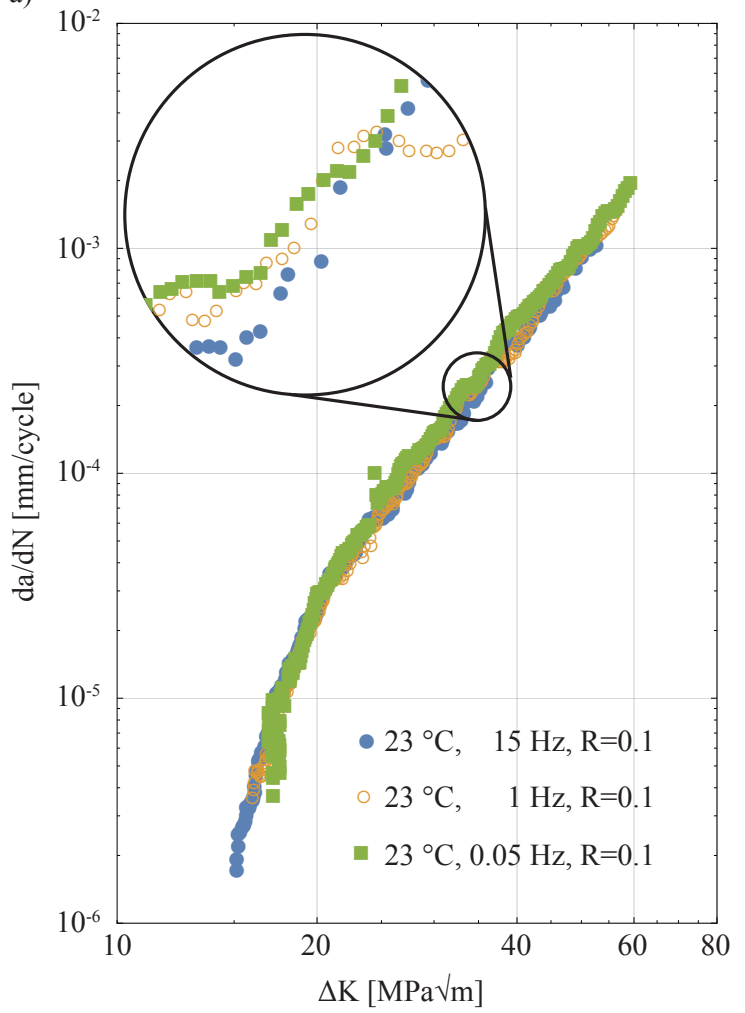

b)

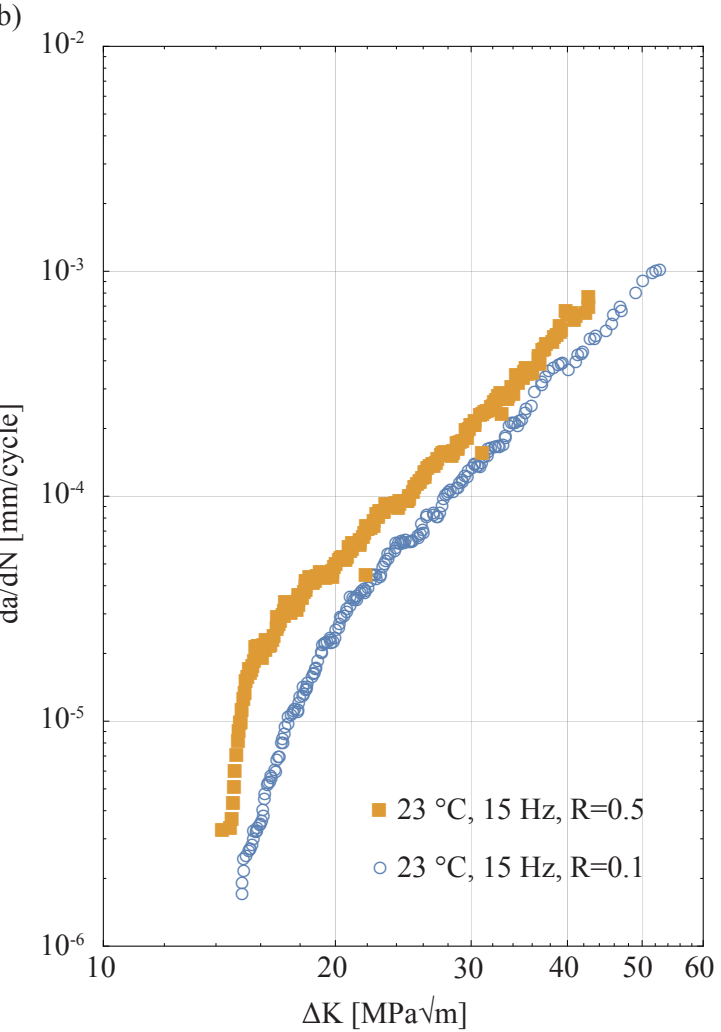

Figure 2: Crack growth rate $d a / d N$ vs. $\Delta K$ at $23{ }^{\circ} \mathrm{C}$ for (a) $R=0.1$ and, (b) $f=15 \mathrm{~Hz}$ for $R=0.1$ and $R=0.5$. 

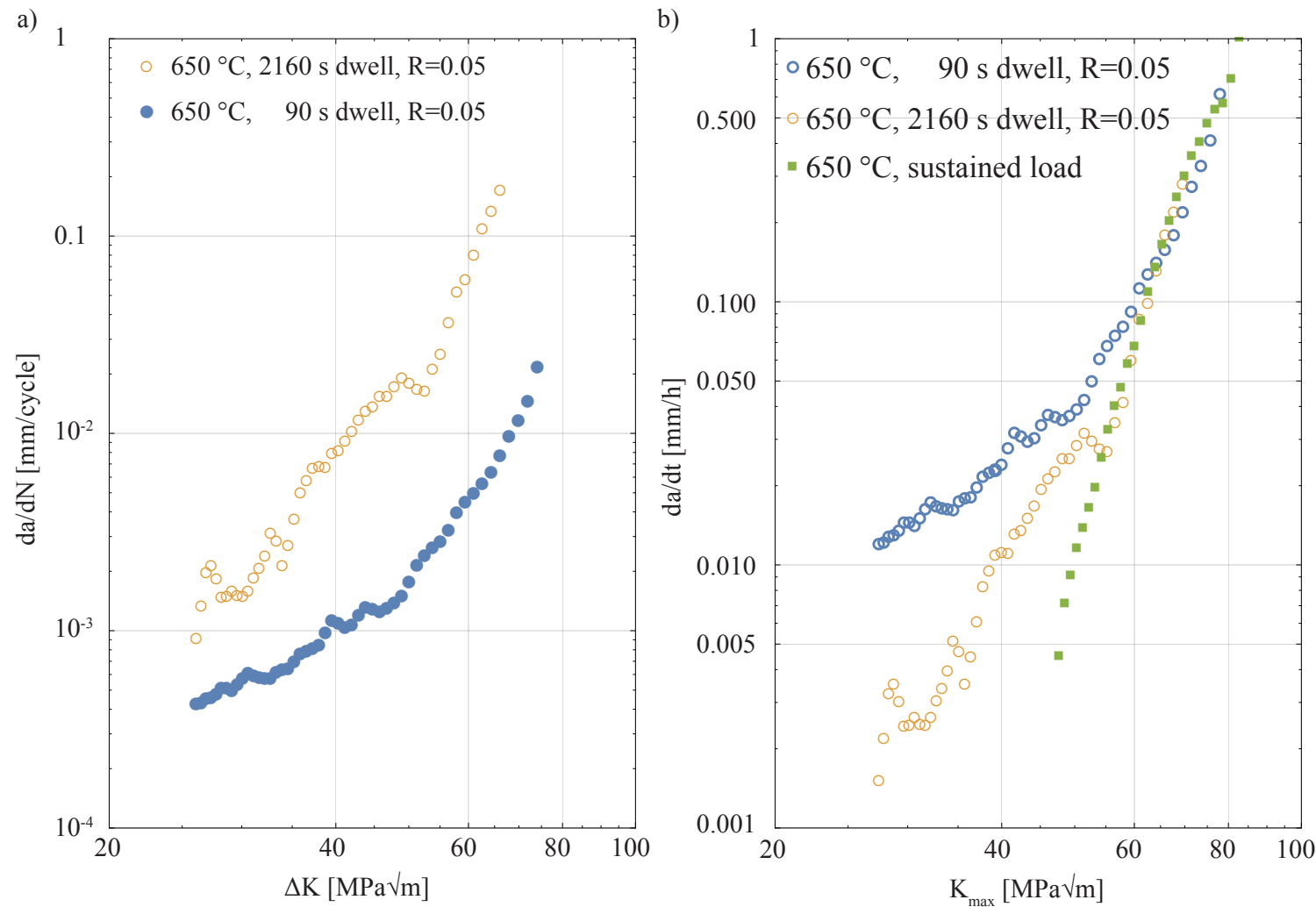

Figure 3: (a) Crack growth rate $d a / d N$ vs. $\Delta K$ at $650{ }^{\circ} \mathrm{C}$ for $R=0.5$, and dwell-times of $2160 \mathrm{~s}$ and $90 \mathrm{~s}$. (b) Time dependent crack growth, $d a / d t$ vs. $K_{\max }$ at $650{ }^{\circ} \mathrm{C}$. 


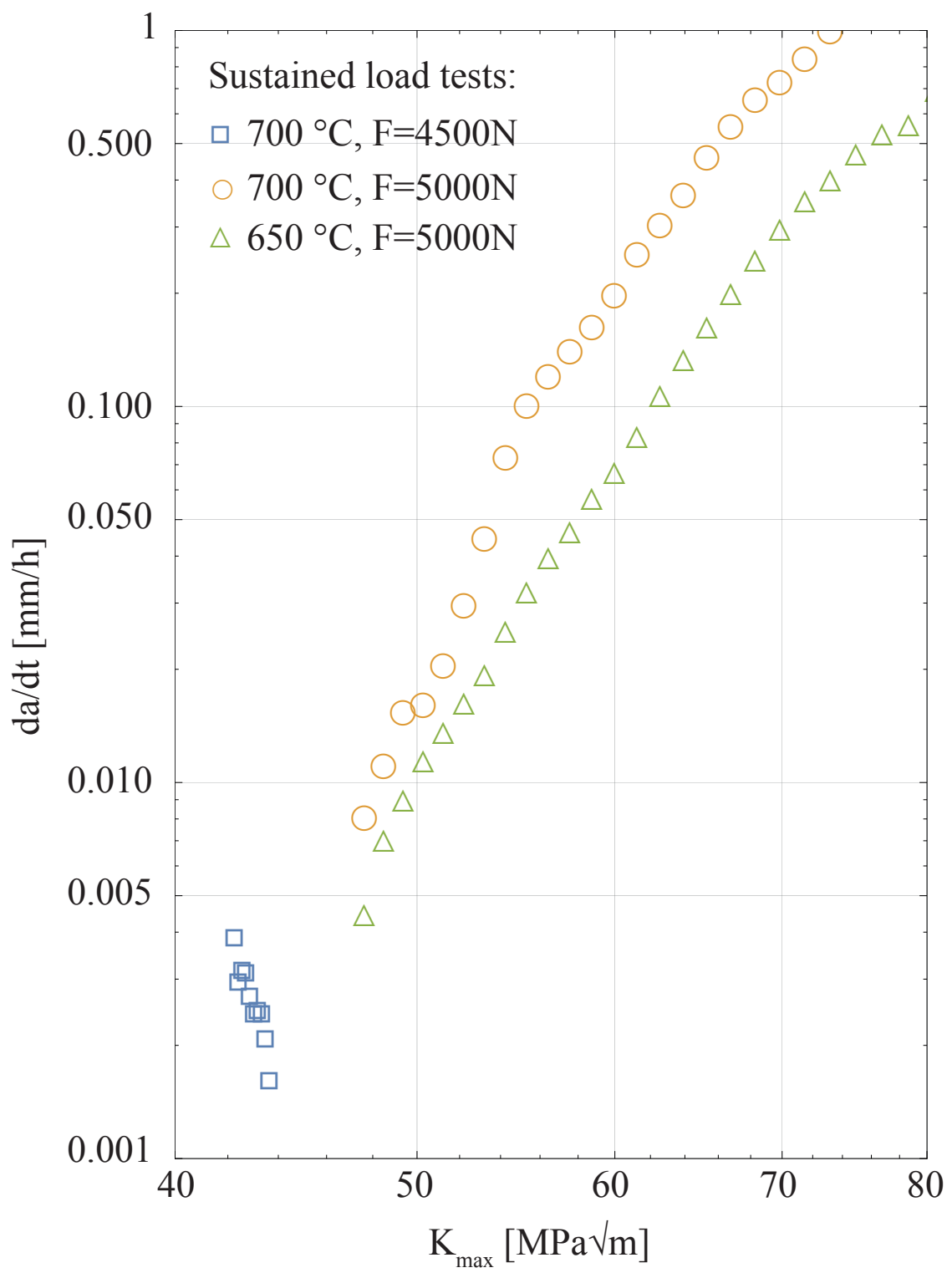

Figure 4: Sustained load crack growth rate $d a / d t$ vs. $K_{\max }$ at $700{ }^{\circ} \mathrm{C}\left(650{ }^{\circ} \mathrm{C}\right.$ data included for comparison). There is an apparent threshold at $K_{\max } \approx 45 \mathrm{MPa} \sqrt{\mathrm{m}}$, below which the crack growth is arrested. 

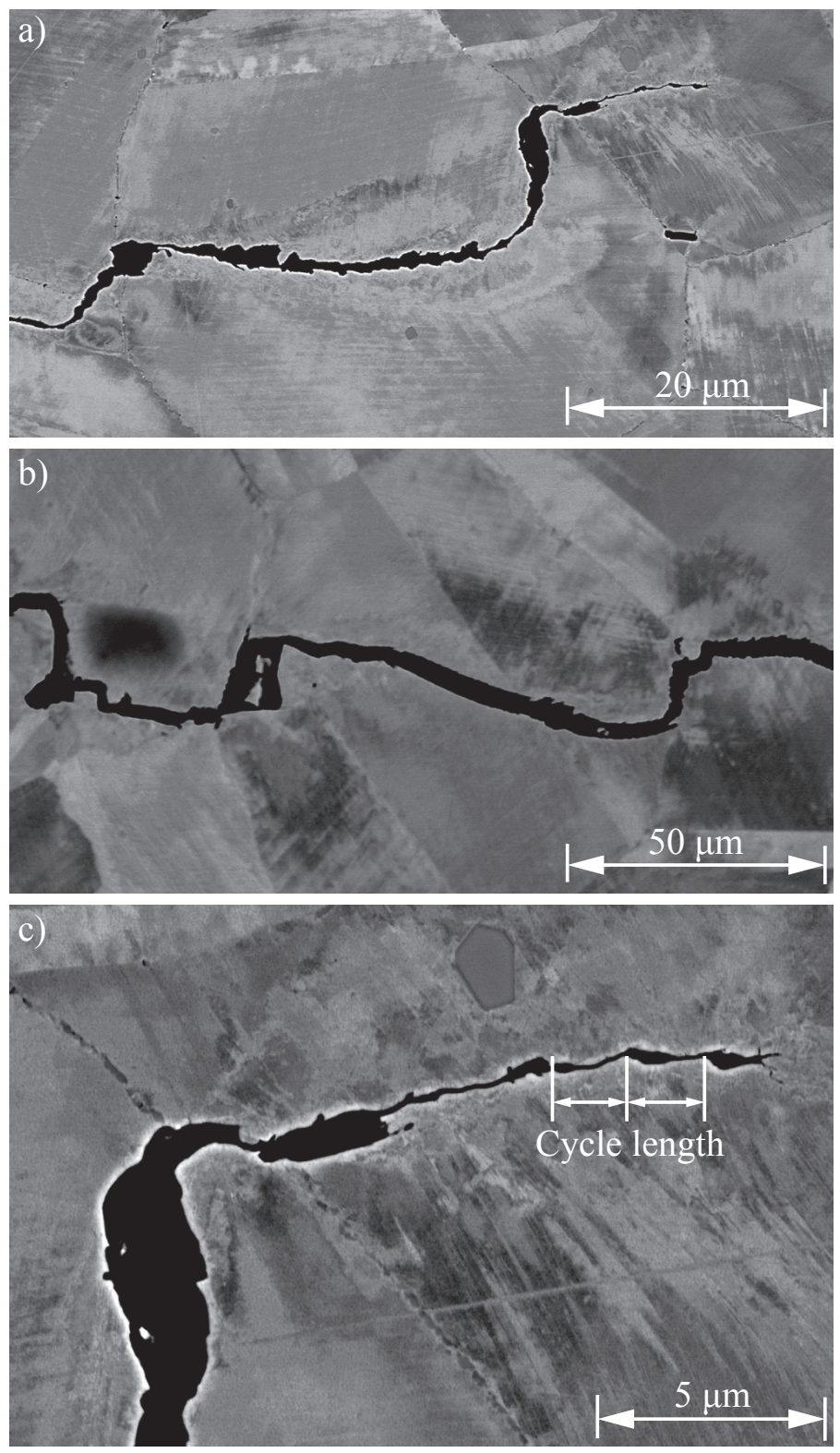

Figure 5: A room temperature fatigue sample run with a sinusoidal test frequency of $f=0.05 \mathrm{~Hz}$ and stress ratio $R=0.1$ showing: (a) The crack tip. (b) The regular cracking behaviour being transgranular. (c) The crack tip and cycle length. 


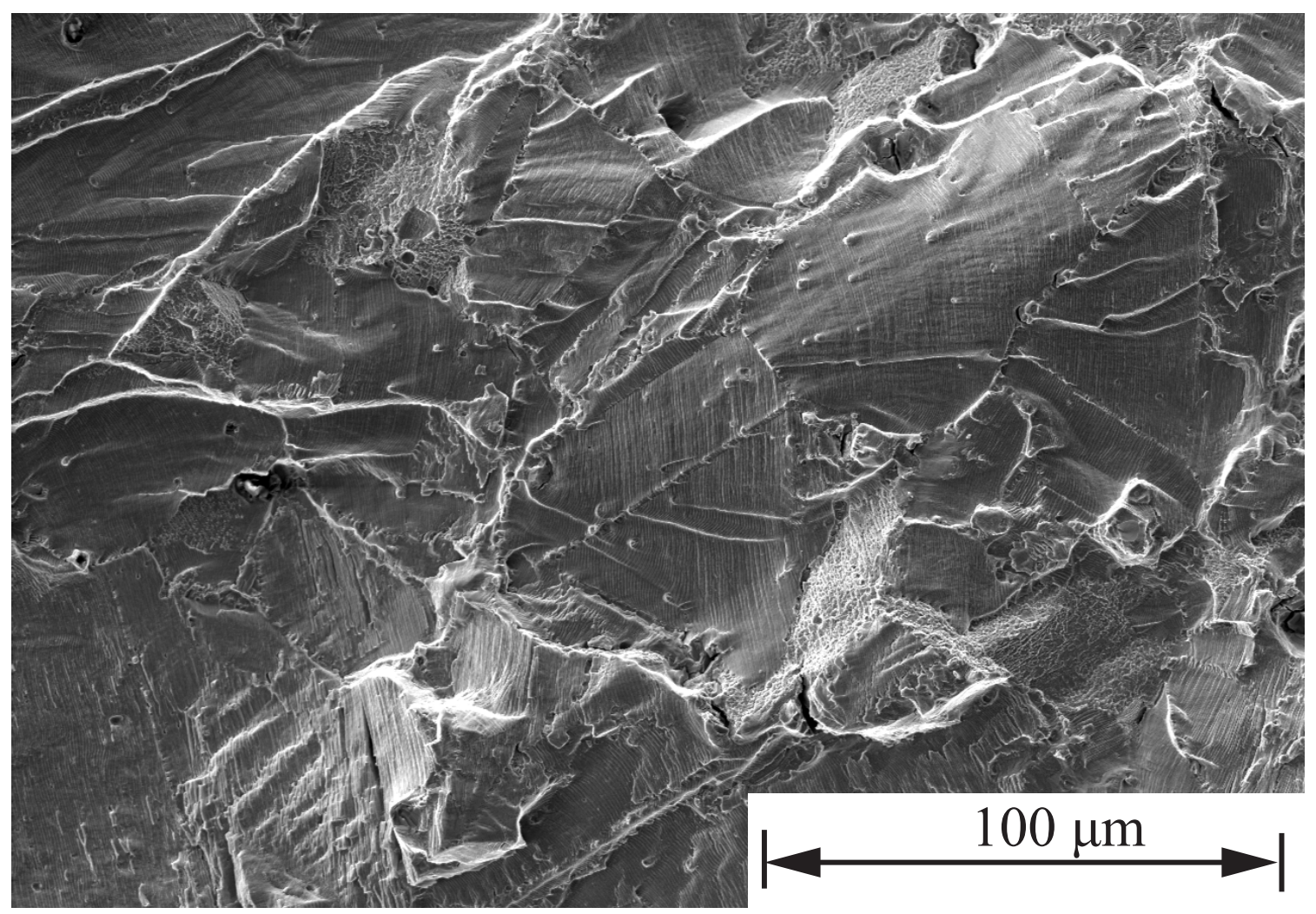

Figure 6: The general fracture surfaces of a fatigued room temperature sample. 

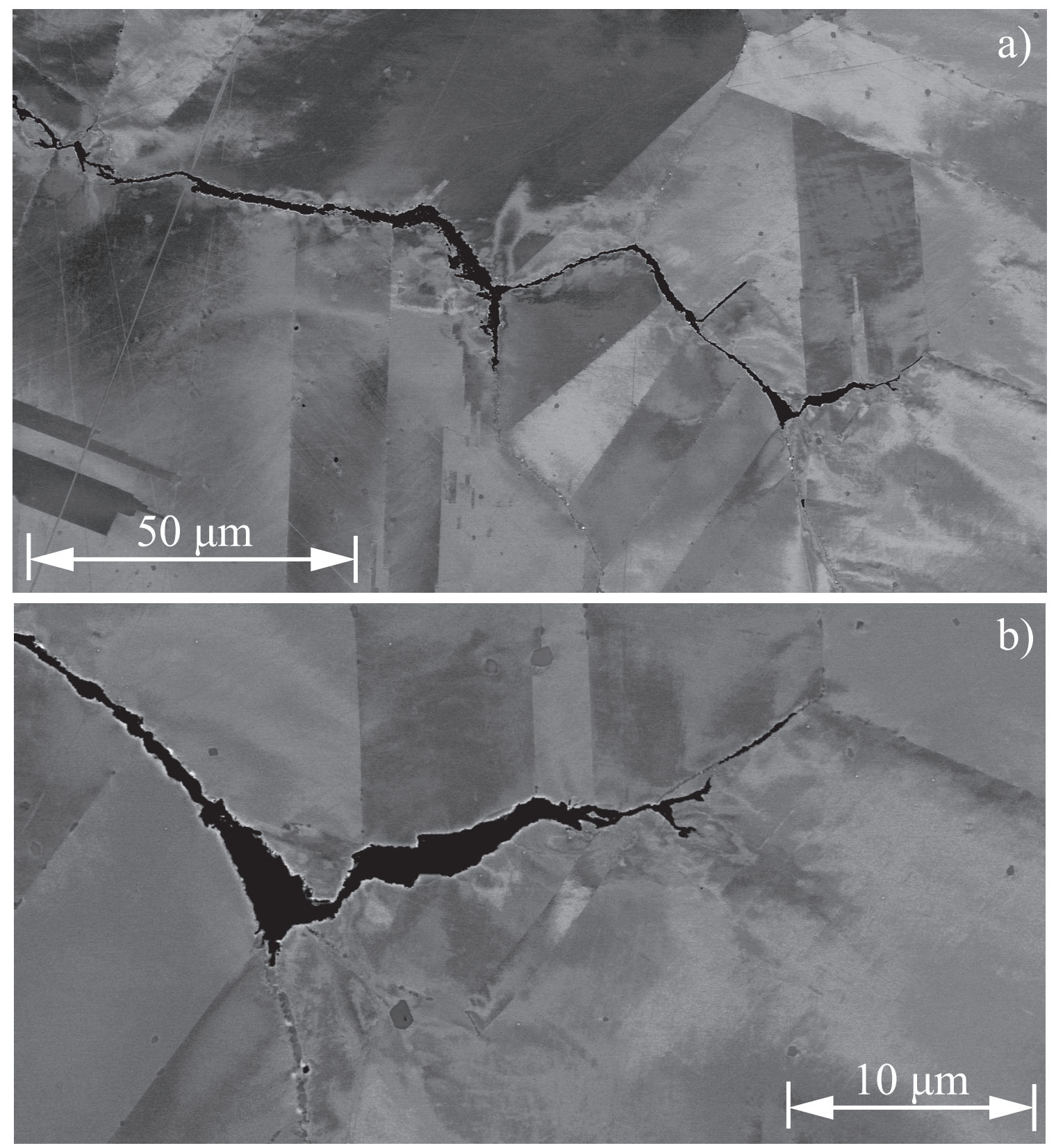

Figure 7: The $650{ }^{\circ} \mathrm{C}, 2160 \mathrm{~s}$ dwell-time sample showing: (a) The regular cracking behaviour being intergranular. (b) The crack tip. 

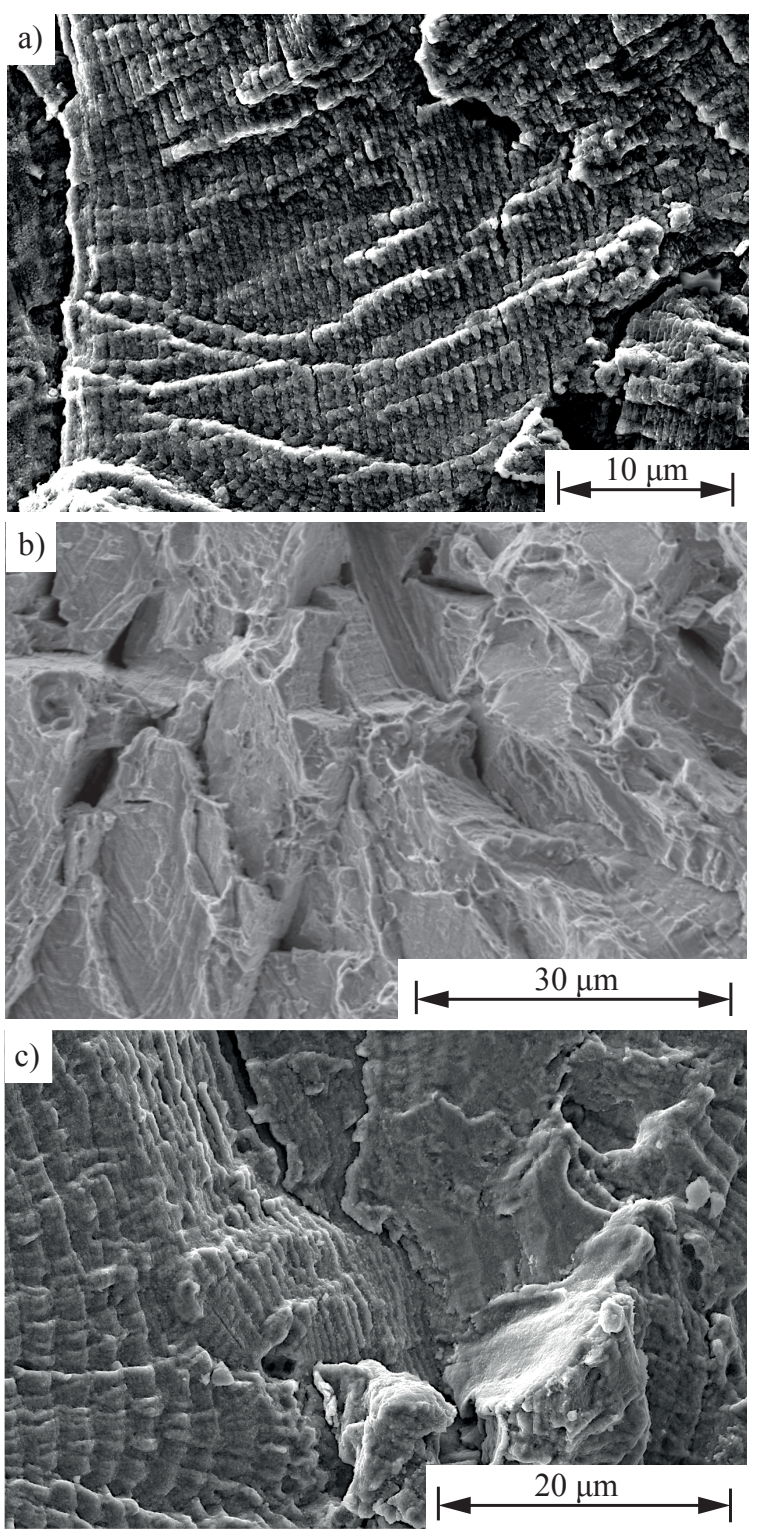

Figure 8: Fracture surfaces of the $90 \mathrm{~s}$ dwell-time sample, the fatigue part taken before the transition between cyclic and time-dependent crack growth, at $\sim 40 \mathrm{MPa} \sqrt{\mathrm{m}}$, and after the transition at $\sim$ $60 \mathrm{MPa} \sqrt{\mathrm{m}}$ (a) Fatigue striations.(b) The creep area, $d a / d t$. (c) Brittle striations. 

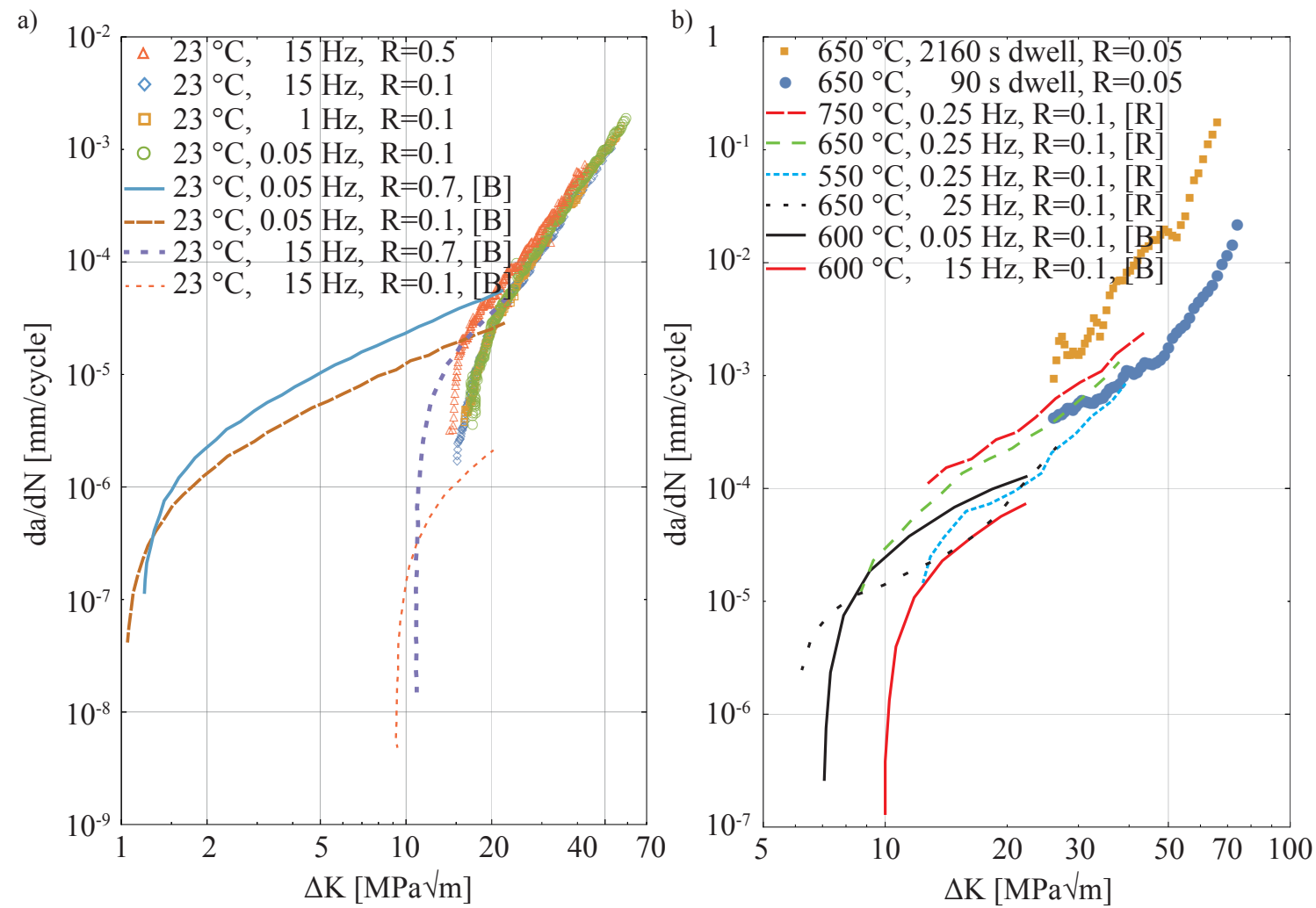

Figure 9: (a) A comparison of our room temperature tests (dots) with data fitted from [10] by Buckson and Ojo (dashed lines) noted [B]. (b) A comparison of our dwell-time tests (dots) with data fitted from [11-13] by Rozman (dashed lines) noted [R], and from [10] by Buckson and Ojo (solid lines) noted [B]. 


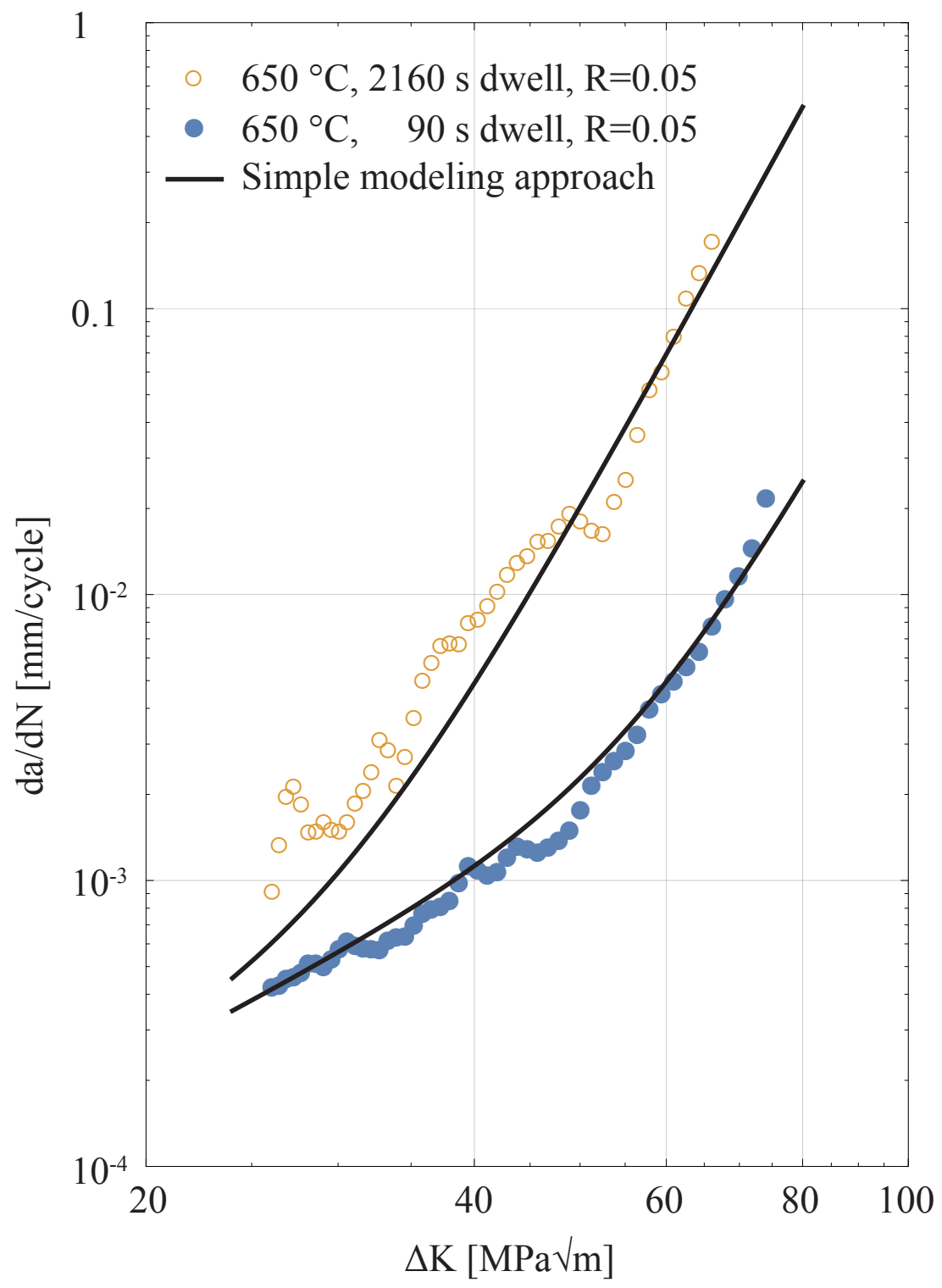

Figure 10: A simple model of the $650{ }^{\circ} \mathrm{C}$ dwell-fatigue crack growth based on the low- $K$ part of the $90 \mathrm{~s}$ dwell-time test and the sustained load test, showing a good fit to both the $90 \mathrm{~s}$ dwell-time test as well as the $2160 \mathrm{~s}$ dwell-time test. 


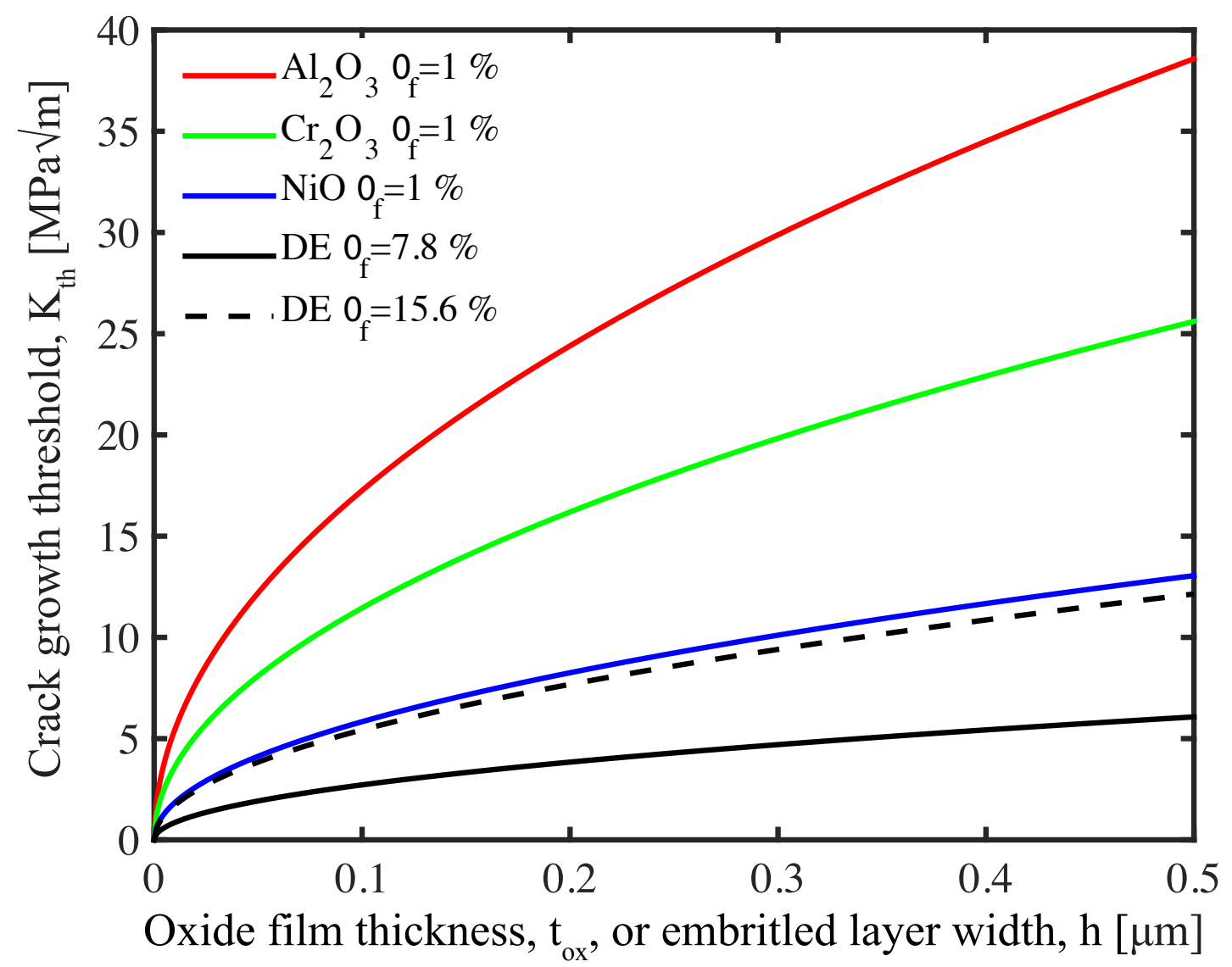

Figure 11: Predicted crack growth threshold as a function of oxide film or embrittled zone thickness. 


\section{List of Tables}

1 Composition of elements for Haynes 282 in wt\% . . . . . . . . . . . 34

2 Summary of ambient temperature fatigue crack growth tests. . . . . . 35

3 Summary of elevated temperature crack growth tests. . . . . . . . . . 36

4 Parameters for calculating the crack growth thresholds. . . . . . . . . 37 
Table 1: Composition of elements for Haynes 282 in wt\%.

\begin{tabular}{l|ccccccccccccccc}
\hline Alloy & $\mathrm{Ni}$ & $\mathrm{Cr}$ & $\mathrm{Co}$ & $\mathrm{Mo}$ & $\mathrm{Ti}$ & $\mathrm{Al}$ & $\mathrm{Fe}$ & $\mathrm{Nb}$ & $\mathrm{C}$ & $\mathrm{Si}$ & $\mathrm{Mn}$ & $\mathrm{Cu}$ & $\mathrm{Ta}$ & $\mathrm{W}$ & $\mathrm{B}$ \\
\hline Haynes 282 & 56.875 & 19.57 & 10.33 & 8.71 & 2.24 & 1.48 & 0.50 & 0.10 & 0.063 & 0.05 & 0.04 & 0.01 & 0.01 & 0.01 & 0.005 \\
\hline
\end{tabular}


Table 2: Summary of ambient temperature fatigue crack growth tests.

\begin{tabular}{ccc}
\hline Frequency & $R$-ratio & Load range $\Delta P$ \\
\hline $15 \mathrm{~Hz}$ & 0.1 & $2500 \mathrm{~N}$ \\
$1 \mathrm{~Hz}$ & 0.1 & $2500 \mathrm{~N}$ \\
$0.05 \mathrm{~Hz}$ & 0.1 & $2500 \mathrm{~N}$ \\
$15 \mathrm{~Hz}$ & 0.5 & $2500 \mathrm{~N}$ \\
\hline
\end{tabular}


Table 3: Summary of elevated temperature crack growth tests.

\begin{tabular}{cccc}
\hline Temperature & Loading condition & Load & $R$-ratio \\
\hline $650{ }^{\circ} \mathrm{C}$ & $90 \mathrm{~s}$ dwell-time & $\Delta P=3500 \mathrm{~N}$ & $R=0.05$ \\
$650{ }^{\circ} \mathrm{C}$ & 2160 s dwell-time & $\Delta P=3500 \mathrm{~N}$ & $R=0.05$ \\
$650{ }^{\circ} \mathrm{C}$ & Sustained load & $P=5000 \mathrm{~N}$ & - \\
$700{ }^{\circ} \mathrm{C}$ & Sustained load & $P=4500 \mathrm{~N}$ & - \\
$700{ }^{\circ} \mathrm{C}$ & Sustained load & $P=5000 \mathrm{~N}$ & - \\
\hline
\end{tabular}


Table 4: Parameters for calculating the crack growth thresholds.

\begin{tabular}{llcccc}
\hline Parameter & Meaning & Matrix & $\mathrm{Cr}_{2} \mathrm{O}_{3}$ & $\mathrm{NiO}$ & $\mathrm{Al}_{2} \mathrm{O}_{3}$ \\
\hline$\sigma_{y}[\mathrm{MPa}]$ & Matrix yield strength & 650 & - & - & - \\
$\nu[-]$ & Poisson's ratio & 0.33 & - & - & - \\
$E_{m}[\mathrm{GPa}]$ & Matrix Young's modulus & 180 & - & - & - \\
$\beta[1 /$ at. $\%]$ & Constant & $5-10$ & - & - & - \\
$C_{0}[$ at. $\%]$ & Solubility constant & 8.3 & - & - & - \\
$\Delta H_{s}^{0}[\mathrm{~kJ} /$ mole] & Heat of solution & 55 & - & - & - \\
$\epsilon_{f}[-]$ & Fracture strain & $0.078-0.156$ & 0.01 & 0.01 & 0.01 \\
$E_{\text {ox }}[\mathrm{GPa}]$ & Oxide Young's modulus & - & 143.6 & 260 & 361.9 \\
$\epsilon_{t r}[-]$ & Transformation strain & - & 5.96 & 0.75 & 5.19 \\
\hline
\end{tabular}

